\title{
Anticoagulant Utilization and Direct Oral Anticoagulant Prescribing in Patients with Nonvalvular Atrial Fibrillation
}

\author{
Priscilla Shum, Gordon Klammer, Dale Toews, and Arden Barry
}

\begin{abstract}
Background: Direct oral anticoagulants (DOACs) are indicated for prevention of stroke and embolism in patients with nonvalvular atrial fibrillation (NVAF). These agents have been shown to be non-inferior to warfarin in terms of efficacy and safety. However, their uptake in practice has been variable, and prescribed dosages may be inconsistent with manufacturer recommendations.
\end{abstract}

Objectives: To evaluate patterns of oral anticoagulant use in patients with NVAF, including determination of patient characteristics associated with the prescribing of warfarin or DOACs and whether prescribed dosages of DOACs were concordant with manufacturer recommendations.

Methods: This retrospective chart review was conducted from April to September 2017 at Abbotsford Regional Hospital, Abbotsford, British Columbia. Patients at least 18 years of age with NVAF and CHADS-65 score of 1 or higher were included. Patients with contraindications to oral anticoagulants, those with reversible atrial fibrillation, and those undergoing renal dialysis were excluded. The dosage of DOACs was categorized as too low, too high, or correct in relation to manufacturer recommendations for the Canadian product.

Results: A total of 120 patients were included. At discharge, 83 (69\%) of the patients had a prescription for DOAC, $25(21 \%)$ had a prescription for warfarin, and $12(10 \%)$ had no prescription for an oral anticoagulant. There were no statistically significant differences between the warfarin and DOAC groups with respect to patient characteristics. Among the 56 patients for whom a full DOAC dose was indicated, 7 (13\%) received a dose that was too low. Among the 23 patients for whom a full DOAC dose was not indicated, $4(17 \%)$ received a dose that was too high.

Conclusions: At the study hospital, most patients with NVAF and CHADS-65 score of at least 1 had a discharge prescription for DOAC. Patient characteristics appeared to be similar between the warfarin and DOAC groups. For a notable proportion of patients who received a DOAC, the dosage was incorrect. Appropriate prescribing of oral anticoagulants could be further improved by education for prescribers and involvement of hospital pharmacists.

\section{RÉSUMÉ}

Contexte : Les anticoagulants oraux directs (AOD) sont indiqués pour prévenir les AVC et les embolies parmi les patients atteints de fibrillation auriculaire non valvulaire (FANV). Il a été démontré que l'efficacité et l'innocuité de ces agents n'étaient pas inférieures à la warfarine. Cependant, leur adoption dans la pratique est inégale, et les doses prescrites peuvent être contraires aux recommandations des fabricants.

Objectifs : Évaluation des habitudes d'utilisation des anticoagulants oraux pour les patients atteints de FANV, y compris la définition des caractéristiques des patients associées à la prescription de la warfarine ou des AOD, ainsi que de la conformité des doses prescrites de ces derniers aux recommandations des fabricants.

Méthodes : Cet examen rétrospectif des dossiers a été mené d'avril à septembre 2017 à l'Hôpital régional d'Abbotsford à Abbotsford, en Colombie-Britannique. Des patients âgés d'au moins 18 ans, atteints de FANV et ayant un score CHADS-65 d'au moins 1, ont été inclus dans l'étude. Les patients présentant une contre-indication aux anticoagulants oraux, ceux atteints de fibrillation auriculaire réversible et ceux soumis à une dialyse rénale en ont été exclus. La dose d'AOD destinés au marché canadien a été catégorisée comme trop faible, trop élevée ou correcte par rapport aux recommandations du fabricant.

Résultats : Cent-vingt patients au total ont participé à l'étude. Au moment du congé, 83 (69\%) d'entre eux avaient une prescription d'AOD, 25 (21\%) avaient une prescription de warfarine et $12(10 \%)$ n'avaient pas de prescription d'anticoagulant oral. En ce qui concerne les caractéristiques des patients, il n'y avait aucune différence statistique notable entre les groupes ayant reçu une prescription de warfarine et ceux ayant reçu une prescription d'AOD. Des 56 patients qui avaient reçu une indication de dose complète d'AOD, sept (13\%) ont reçu une dose trop faible. Des 23 patients qui n'avaient pas reçu d'indication de dose complète d'AOD, quatre (17\%) ont reçu une dose trop élevée.

Conclusions : À l'hôpital où s'est déroulée l'étude, la plupart des patients atteints de FANV et ceux ayant un score CHADS-65 d'au moins 1 recevaient une prescription d'AOD au moment du congé. Les caractéristiques des patients semblaient similaires entre les groupes ayant reçu une 
Keywords: atrial fibrillation, stroke, anticoagulants, medical records, retrospective studies

Can J Hosp Pharm. 2019;72(6):428-34 prescription de warfarine et ceux ayant reçu une prescription d'AOD. La dose d'AOD reçue par une proportion notable de patients était incorrecte. La prescription appropriée d'anticoagulants oraux pourrait encore être améliorée si on sensibilisait les prescripteurs avec la collaboration des pharmaciens d'hôpitaux.

Mots-clés: fibrillation auriculaire, AVC, anticoagulants, dossiers médicaux, examen rétrospectif

\section{INTRODUCTION}

A trial fibrillation is the most common cardiac arrhythmia in North America, affecting approximately 200000 Canadians in 2018. ${ }^{1}$ The formation of atrial thrombi, which can occur with any type of atrial fibrillation, may result in ischemic stroke, the most common manifestation of embolization. ${ }^{2}$ In use since the 1950s, warfarin is a vitamin $\mathrm{K}$ antagonist indicated for prevention of stroke in patients with atrial fibrillation. ${ }^{3}$ Trials have demonstrated that warfarin is effective in reducing the risk of stroke by two-thirds relative to placebo, as well as showing superiority when compared with the combination of acetylsalicylic acid (ASA) and clopidogrel. ${ }^{3,4}$ Despite the efficacy of warfarin, its use is limited by its narrow therapeutic range, the need for frequent monitoring of international normalized ratio (INR) and corresponding dose adjustments, and many drug-drug and drug-food interactions. ${ }^{5-7}$

Since 2010, four direct oral anticoagulants (DOACs) apixaban, dabigatran, edoxaban, and rivaroxaban-have been approved in Canada for prevention of stroke in patients with nonvalvular atrial fibrillation (NVAF). ${ }^{5-7}$ This form of atrial fibrillation is defined as atrial fibrillation not associated with rheumatic mitral stenosis of any severity, moderate-to-severe nonrheumatic mitral stenosis, or mechanical heart valves. ${ }^{6}$ Relative to warfarin, DOACs offer therapeutic and lifestyle advantages, including rapid onset and offset of action, no requirement for INR monitoring, fewer drug-drug and drug-food interactions, and fewer lifestyle modifications..$^{5-7}$ The landmark trials for DOACs, specifically RE-LY, ${ }^{8}$ ROCKET-AF, ${ }^{9}$ ARISTOTLE, ${ }^{10}$ and ENGAGE AF-TIMI $48,{ }^{11}$ have shown that all 4 DOACs are at least noninferior to warfarin in the reduction of stroke and systemic embolism. There was also a reduction in hemorrhagic stroke and intracranial hemorrhage with all 4 DOACs relative to warfarin. ${ }^{8-11}$ None of the DOACs were associated with an increase in major bleeding, but there was an increase in gastrointestinal bleeding events associated with dabigatran (at $150 \mathrm{mg}$ twice daily), rivaroxaban, and edoxaban (at $60 \mathrm{mg}$ once daily). ${ }^{8-11}$ Postmarketing, real-world data pertaining to the efficacy and safety of DOACs have been consistent with the landmark trials. ${ }^{12}$ The current atrial fibrillation guidelines of the Canadian Cardiovascular Society
(CCS) endorse the preference for DOACs over warfarin in patients with a CHADS-65 score of 1 or higher. ${ }^{6}$ The DOACs are also recommended as suitable alternatives to warfarin in the atrial fibrillation guidelines of both the American Heart Association (published in 2014) (n) $^{5}$ and the European Society of Cardiology (published in 2016). ${ }^{7}$

Around the world, uptake of DOACs in practice has been variable. In Canada, a population-based descriptive analysis from Ontario demonstrated rapid uptake of DOACs within 2 years after approval. ${ }^{13}$ Over a 24-month period (October 2010 to September 2012), there was a 20-fold increase in DOAC prescriptions, accounting for $21 \%$ of all anticoagulant prescriptions. ${ }^{13}$ In contrast, a prospective survey using the European EORP-AF (EURObservational Research Programme Atrial Fibrillation) registry showed that of the 3119 patients enrolled, $72 \%$ received warfarin, but only $8 \%$ received a DOAC. ${ }^{14}$ Furthermore, several recent studies of DOAC prescribing in practice have shown that prescribed doses are often inconsistent with the manufacturer's recommendations. ${ }^{15,16}$ In a study of dabigatran utilization in the ORBIT-AF (Outcomes Registry for Better Informed Treatment of Atrial Fibrillation), more than half of the patients with severe kidney disease did not receive the recommended reduced dose, whereas $10 \%$ of those with normal renal function received a dose that was lower than recommended. ${ }^{15}$ Similarly, in a recently published study by Yao and others, ${ }^{16}$ of the approximately 1500 patients with an indication for renal adjustment of DOAC dose, $43 \%$ received standard dosages. In contrast, among roughly 13000 patients with no indication for renal adjustment of DOAC dose, $13 \%$ may have received a dose that was too low. ${ }^{16}$

The purpose of this study was to describe and evaluate the local prescribing patterns of anticoagulant therapy in patients with NVAF at the Abbotsford Regional Hospital (ARH) located in Abbotsford, British Columbia. This was a quality assurance project to ensure safe and effective prescribing of oral anticoagulants for patients in the $\mathrm{ARH}$ region. In addition, patient characteristics associated with the use of warfarin or a DOAC were evaluated, as well as the concordance of DOAC prescribing with manufacturer recommendations. 


\section{METHODS}

This single-centre retrospective study involved review of electronic medical records. Health records personnel identified patients admitted to the ARH between April 1, 2017, and September 30, 2017, who had a documented diagnosis of atrial fibrillation, based on International Statistical Classification of Diseases and Related Health Problems, 10th revision (ICD-10) coding. This study was deemed to be a quality assurance project and thus exempt from full review by the ARH Research Ethics Board.

\section{Study Population}

Patients aged 18 years or older with an indication for long-term oral anticoagulation (defined as CHADS-65 score $\geq 1$ ) were included. On the basis of information documented in the admission consultation notes and discharge summary, patients were excluded if they had mitral stenosis or a mechanical heart valve, a contraindication to taking an oral anticoagulant (e.g., hypersensitivity, active intracranial bleeding, pregnancy), a left atrial appendage exclusion device, or atrial fibrillation due to reversible causes, or if they were receiving renal dialysis. If a patient had multiple admissions within the study period, only the most recent eligible admission was included.

\section{Data Collection}

A standardized data collection form was used. Most of the data collection was performed by one investigator (P.S.), for consistency. Data for the following patient characteristics were collected: demographic and physical characteristics (age, sex, weight), anticoagulant prescribed on discharge (apixaban, dabigatran, edoxaban, rivaroxaban, warfarin, or none), components of the CHADS-65 score, components of the HAS-BLED score, and other medical conditions. Components of the CHADS-65 score were heart failure; hypertension; age older than 65 years; diabetes mellitus; and a history of ischemic stroke, transient ischemic attack, or arterial thromboembolism. ${ }^{6}$ Heart failure was defined, in accordance with the CCS, ${ }^{6}$ as moderate-to-severe systolic dysfunction, signs and symptoms of heart failure with reduced ejection fraction, or recent decompensated heart failure that required hospitalization irrespective of ejection fraction. Components of the HAS-BLED score were uncontrolled hypertension (systolic blood pressure $>160 \mathrm{~mm} \mathrm{Hg}$ ), abnormal renal function (long-term dialysis, renal transplant, or serum creatinine $\geq 200 \mu \mathrm{mol} / \mathrm{L}$ ), abnormal liver function (cirrhosis; bilirubin greater than 2 times the upper limit of normal; or aspartate aminotransferase, alanine aminotransferase, or alkaline phosphatase greater than 3 times the upper limit of normal), history of ischemic or hemorrhagic stroke, history of gastrointestinal bleeding or other major bleeding (excluding hemorrhagic stroke), age older than 65 years, use of nonsteroidal anti-inflammatory drugs or antiplatelet agent (ASA, clopidogrel, prasugrel, or ticagrelor), and excessive alcohol use ( $>8$ drinks per week). ${ }^{17}$ The CHADS-65 and HAS-BLED scores were calculated using the available data collected, with the exception of labile INR and anemia for the HAS-BLED score, as it was not feasible to reliably collect these data from the medical records. Uncontrolled hypertension was based on the last reading before discharge. Major bleeding was defined as bleeding that led to hospitalization, a decrease in hemoglobin of more than $20 \mathrm{~g} / \mathrm{L}$, or a need for transfusion. The DOAC dose was assessed as too low, too high, or correct in relation to the manufacturer's recommendations for the Canadian product. In accordance with recommendations in the European Heart Rhythm Association's practical guide on the use of new oral anticoagulants in patients with NVAF, common drug interactions were also taken into account to determine whether adjustment of the DOAC dose was warranted. ${ }^{18}$

\section{Statistical Analysis}

Prescribing patterns were described using proportions. Patient characteristics were described using proportions with 95\% confidence intervals for categorical variables and means with standard deviations for continuous variables. Baseline characteristics of patients using warfarin and DOACs were compared using a $\chi^{2}$ test for categorical variables (or the Fisher exact test if the number of patients was less than 5) or the Student $t$ test for continuous variables (or the Welch $t$ test if there was unequal variance between groups). A $p$ value less than 0.05 was considered statistically significant.

\section{RESULTS}

A total of 184 patients were identified, of whom 120 were included in the study (Figure 1). The most common reasons for exclusion were a CHADS-65 score less than 1 and atrial fibrillation due to reversible causes. There was a higher proportion of men in the warfarin group, and patient weight was numerically higher in the group receiving no oral anticoagulant (Table 1). The mean CHADS-65 score was comparable across all 3 groups, and the mean HAS-BLED score was numerically higher in the group receiving no oral anticoagulant. This group also had a higher proportion of patients receiving either ASA or a P2Y12 inhibitor. However, there were no statistically significant differences between the warfarin and DOAC groups with respect to patient characteristics, comorbid medical conditions, or mean CHADS-65 and HAS-BLED scores. An analysis comparing the no oral anticoagulant group to the other groups was not performed because of the low number of patients in that group.

At discharge, most patients $(83 / 120,69 \%)$ had a prescription for a DOAC, and 25 (21\%) had a prescription for warfarin (Figure 2). Twelve (10\%) of the patients had no prescription for an oral anticoagulant at discharge. The most commonly prescribed DOACs were apixaban (42 [35\%] of the 120 patients 
This single copy is for your personal, non-commercial use only.

For permission to reprint multiple copies or to order presentation-ready copies for distribution, contact CJHP at publications@cshp.pharmacy

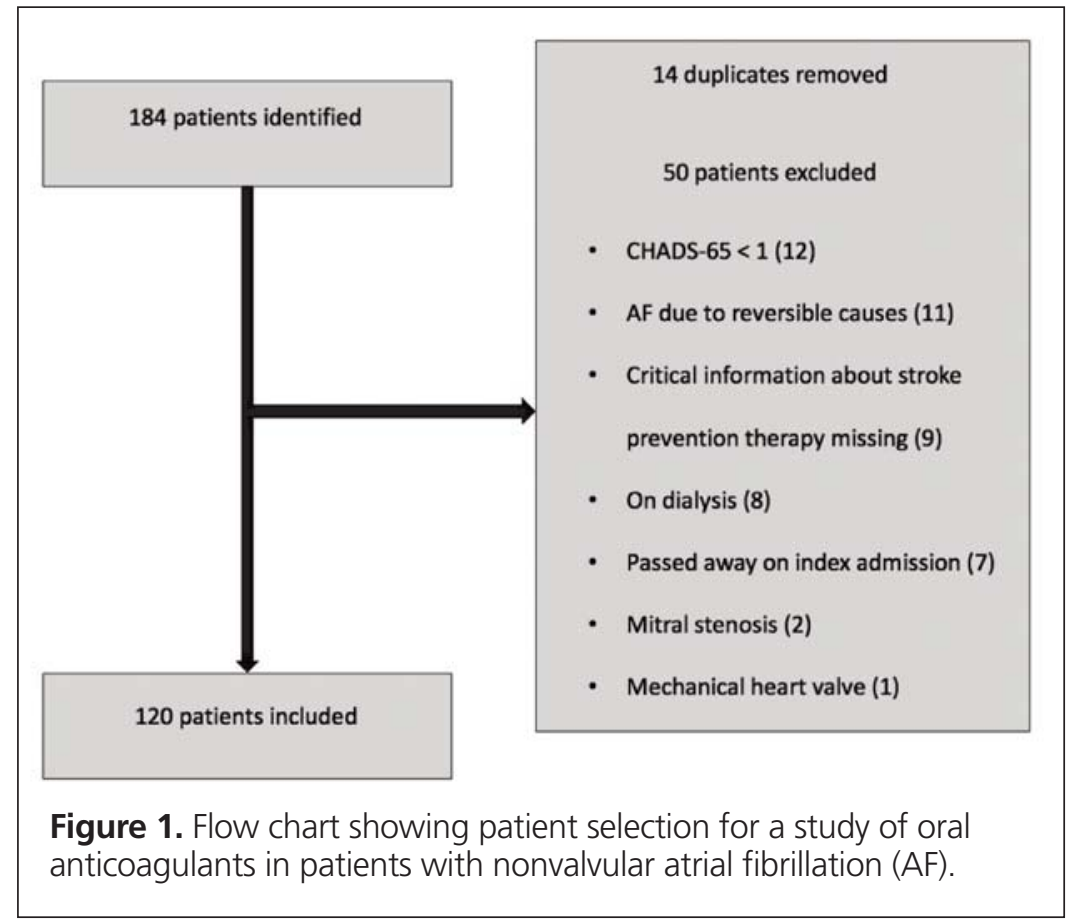

in the study) and rivaroxaban (38/120, 32\%). Only $3(2 \%)$ of the patients had a prescription for dabigatran, and none were receiving edoxaban. Among patients without a prescription for an oral anticoagulant, only 7 had a documented reason: 3 declined to take an oral anticoagulant, 1 had a recent episode of gastrointestinal bleeding, 1 had a recent episode of retroperitoneal bleeding, and 2 were considered to be at high risk of falling.

With respect to DOAC prescribing, data were available for 79 of the 83 patients. A full dose was indicated for most of the patients $(56 / 79,71 \%)$ (Figure 3). Of these patients, 49 (87\%) had the correct dosage prescribed, whereas the remaining 7 (13\%) had a prescribed dosage that was too low. Of the patients for whom a full dose was not indicated (23/79, 29\%), 19 (83\%) had the correct dosage prescribed, whereas the remaining 4 (17\%) had a prescribed dosage that was too high. Of these latter 4 patients, 3 required dose adjustment on the basis of renal function. The fourth patient was taking itraconazole, which-according to Canadian manufacturer's recommendations_-is a contraindication to DOAC therapy.

\section{DISCUSSION}

In the study institution, more than two-thirds of patients with a diagnosis of NVAF had a prescription for a DOAC at discharge, in alignment with the current CCS guideline for atrial fibrillation. ${ }^{6}$ The most commonly prescribed DOACs were apixaban and rivaroxaban. No patients were receiving edoxaban, probably because it is not currently listed on the ARH hospital formulary and is not eligible for provincial drug coverage.
However, 12 patients (10\%) had no prescription for an oral anticoagulant at discharge. Compared with those for whom warfarin or a DOAC was prescribed, these patients had a numerically higher mean HAS-BLED score; therefore, their risk of bleeding may have been the reason no oral anticoagulant was prescribed. In addition, a higher proportion of these patients were taking ASA or a P2Y12 inhibitor, drugs that offer some protection against stroke or systemic embolism in patients with atrial fibrillation. However, ASA monotherapy or ASA in combination with clopidogrel have been shown to be inferior to warfarin in the prevention of stroke and systemic embolism in patients with atrial fibrillation. ${ }^{3,4}$ In addition, the combination of ASA and clopidogrel was associated with a risk of bleeding similar to that of warfarin. ${ }^{4}$ In one case in this study, a high risk of falling was documented as the reason for not prescribing an oral anticoagulant, which may not have been appropriate. In older patients who have a 5\% annual risk for stroke (i.e., CHADS-65 score of approximately 2-3) and who are taking an oral anticoagulant, an analytical model estimated that a patient would have to fall 295 times per year to sustain a subdural hemorrhage. ${ }^{19}$ Therefore, the authors concluded that for most patients, the risk of falling while receiving anticoagulant therapy likely does not exceed the benefit of taking an anticoagulant.

Prescribing of oral anticoagulants for patients with NVAF could be improved at the ARH through means such as education for prescribers and involvement of hospital pharmacists. Targeted education could be offered to prescribers regarding the relative benefits and risks of oral anticoagulant therapy. Such education could help to address common misconceptions about the 
Table 1. Baseline Characteristics of Patients

\begin{tabular}{|c|c|c|c|c|}
\hline \multirow[b]{2}{*}{ Characteristic } & \multicolumn{3}{|c|}{ Drug Therapy Group; No. (\%) of Patients* } & \multirow[b]{2}{*}{$p$ valuet } \\
\hline & $\begin{array}{c}\text { Warfarin } \\
(n=25)\end{array}$ & $\begin{array}{c}\text { DOAC } \\
(n=83)\end{array}$ & $\begin{array}{l}\text { No OAC } \\
(n=12)\end{array}$ & \\
\hline Age (years) (mean \pm SD) & $78 \pm 8.6$ & $79 \pm 11.6$ & $78 \pm 10.8$ & 0.55 \\
\hline Sex, male & $17(68)$ & $43(52)$ & $6(50)$ & 0.15 \\
\hline Weight (kg) (mean \pm SD) & $84.5 \pm 29.5$ & $78.5 \pm 25.3$ & $89.3 \pm 15.6$ & 0.34 \\
\hline \multicolumn{5}{|l|}{ Kidney function } \\
\hline $\begin{array}{l}\text { Serum creatinine }(\mu \mathrm{mol} / \mathrm{L}) \\
(\text { mean } \pm \mathrm{SD})\end{array}$ & $116 \pm 69.4$ & $93 \pm 29.3$ & $99.6 \pm 34.9$ & 0.12 \\
\hline $\mathrm{eGFR}(\mathrm{mL} / \mathrm{min})($ mean $\pm \mathrm{SD})$ & $59 \pm 22.1$ & $63.2 \pm 20.2$ & $61.2 \pm 26.8$ & 0.38 \\
\hline \multicolumn{5}{|l|}{ Liver function } \\
\hline ALT/AST/ALP > 3x ULN & $0(0)$ & $3(4)$ & $2(17)$ & 0.90 \\
\hline Total bilirubin $>2 x$ ULN & $3(12)$ & $4 \quad(5)$ & $0 \quad(0)$ & 0.20 \\
\hline \multicolumn{5}{|l|}{ Concurrent medications } \\
\hline NSAID & $0(0)$ & 1 (1) & $0 \quad(0)$ & 0.90 \\
\hline ASA & $3(12)$ & $12(14)$ & $10(83)$ & 0.90 \\
\hline P2Y12 inhibitor & $1(4)$ & $5(6)$ & $4(33)$ & 0.90 \\
\hline \multicolumn{5}{|l|}{ Comorbidities } \\
\hline Hypertension & $20(80)$ & $62(75)$ & $8(67)$ & 0.59 \\
\hline Heart failure & $15(60)$ & $35(42)$ & $4(33)$ & 0.12 \\
\hline Ischemic stroke/TIA & $6(24)$ & $21(25)$ & $2(17)$ & 0.90 \\
\hline Stable CAD & $7(28)$ & $15(18)$ & $2(17)$ & 0.28 \\
\hline ACS ( $\leq 1$ year $)$ & $0(0)$ & $7 \quad(8)$ & $1(8)$ & 0.20 \\
\hline Arterial thromboembolism & $0 \quad(0)$ & $0 \quad(0)$ & $0 \quad(0)$ & NA \\
\hline Hemorrhagic stroke & $0(0)$ & $0 \quad(0)$ & 1 (8) & NA \\
\hline Gastrointestinal bleed & $0(0)$ & $2(2)$ & 1 (8) & 0.90 \\
\hline Other major bleed & $0(0)$ & 1 (1) & $3(25)$ & 0.90 \\
\hline Diabetes mellitus & $8(32)$ & $19(23)$ & $3(25)$ & 0.36 \\
\hline CKD (stage 2-5) & $10(40)$ & $35(42)$ & $6(50)$ & 0.85 \\
\hline Renal transplant & $0(0)$ & $0 \quad(0)$ & $0 \quad(0)$ & NA \\
\hline Liver cirrhosis & $0(0)$ & $0 \quad(0)$ & $0 \quad(0)$ & NA \\
\hline Current alcohol misuse & $1(4)$ & $4 \quad(5)$ & $0 \quad(0)$ & 0.90 \\
\hline \multicolumn{5}{|l|}{ Scores } \\
\hline CHADS-65 score (mean \pm SD) & $3.1 \pm 1.1$ & $2.8 \pm 1.2$ & $2.6 \pm 1.1$ & 0.30 \\
\hline HAS-BLED score (mean \pm SD) & $1.6 \pm 0.8$ & $1.5 \pm 0.8$ & $2.5 \pm 0.5$ & 0.87 \\
\hline \multicolumn{5}{|c|}{$\begin{array}{l}\text { ACS = acute coronary syndrome, ALP = alkaline phosphatase, } \mathrm{ALT}=\text { alanine aminotransferase, } \mathrm{ASA}=\text { acetylsalicylic acid } \\
\text { AST = aspartate aminotransferase, CAD = coronary artery disease, CKD = chronic kidney disease, } \\
\text { DOAC = direct-acting oral anticoagulant, eGFR = estimated glomerular filtration rate, } \\
\text { NSAID = nonsteroidal anti-inflammatory drug, OAC = oral anticoagulant, } S D=\text { standard deviation, } \\
\text { TIA = transient ischemic attack, ULN = upper limit of normal. } \\
\text { *Except where indicated otherwise. } \\
\text { tFor comparison of patients receiving warfarin with patients receiving DOAC by } \chi^{2} \text { test, Fisher exact test, Student } t \text { test, } \\
\text { or Welch } t \text { test. }\end{array}$} \\
\hline
\end{tabular}

contraindications to oral anticoagulant therapy, such as a patient's risk of falling. A pharmacist-led initiative aimed at improving the prescribing of oral anticoagulants might help to ensure that all patients with NVAF are appropriately assessed for oral anticoagulation, and might also improve documentation to ensure continuity of care and increase awareness among prescribers about pharmacists' ability to address drug therapy issues. Drug therapy issues that hospital pharmacists could help to resolve might include inappropriate prescribing, absence of an approved indication, presence of a contraindication, potential drug-drug and drug-disease interactions, concerns about patient adherence or medication cost, patients' inability to take oral medication, and identification of other clinical considerations (e.g., use of DOACs in patients with obesity or severe renal dysfunction).
Several studies that evaluated oral anticoagulant prescribing patterns have identified patient-specific factors that may influence the prescribing of warfarin in preference to DOACs. ${ }^{13,14,20-24}$ These factors include a history of gastrointestinal bleeding, older age, multiple comorbid medical conditions, and medication cost. At the ARH, it is likely that cost is a barrier only for a minority of patients who do not qualify for provincial drug coverage. To qualify for provincial drug coverage, patients must have had labile INR with warfarin therapy over a 2-month trial period or an inability to monitor INR regularly. ${ }^{25}$ This criterion permits most patients to qualify for provincial drug coverage, and may be why warfarin was prescribed for fewer than one-quarter of patients. When patient characteristics were compared between those with 


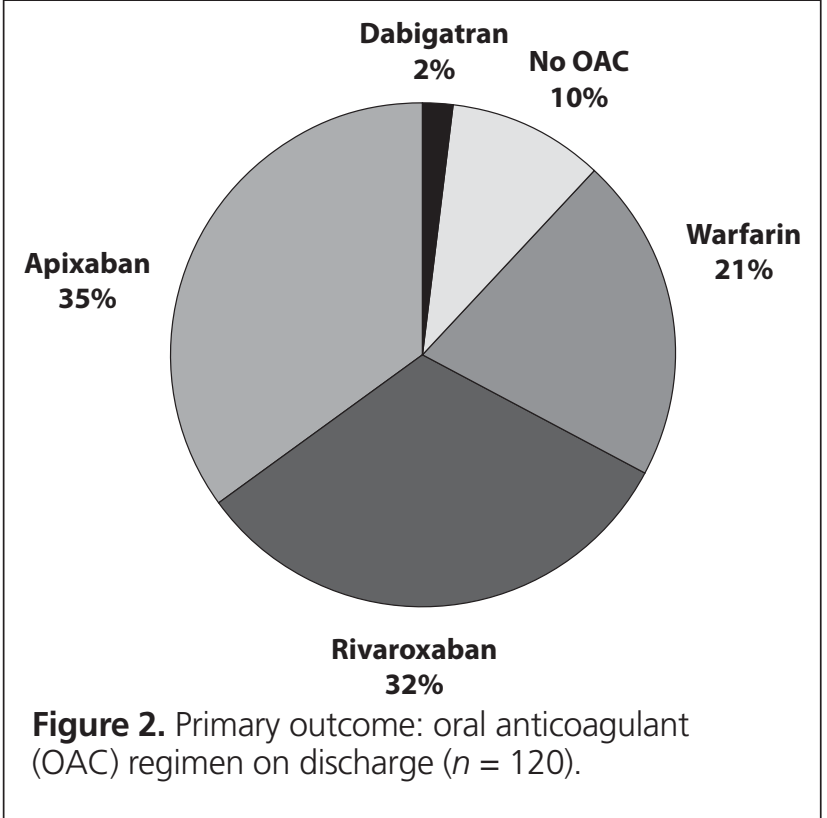

a prescription for warfarin and those receiving a DOAC, no statistically significant differences were identified. However, this analysis may have been underpowered because of the small sample size. Further prospective studies assessing patients' and prescribers' perspectives may help to illuminate the rationale behind oral anticoagulant prescribing patterns.

In terms of DOAC prescribing in the present study, the incidence of patients receiving a higher-than-recommended dose was below that reported by Yao and others ${ }^{16}$ (17\% versus $43 \%$, respectively). The study by Yao and others ${ }^{16}$ took place in the United States, in a health care setting similar to the ARH region, so a greater similarity in results might have been expected. One possible explanation for the observed difference is increased familiarity with these medications among prescribers in the current study, given that data in the earlier study were obtained between 2010 and 2015. The incidence of patients receiving a lower-than-recommended dose was similar in the current study and the study by Yao and others ${ }^{16}(12.5 \%$ versus $13 \%$, respectively).

This study had several limitations that warrant discussion. First, it was a retrospective study, and thus relied on the accuracy and completeness of documentation in the medical records. As well, because of the small sample size, the study may have been underpowered to identify between-group differences. No statistical analysis was performed to compare the group receiving no oral anticoagulant with the other groups, because there were only a few patients who did not receive any oral anticoagulant. Finally, this study did not assess adherence or cost concerns, which might have affected prescribing patterns. As stated above, future prospective studies may help to further clarify prescribing patterns.

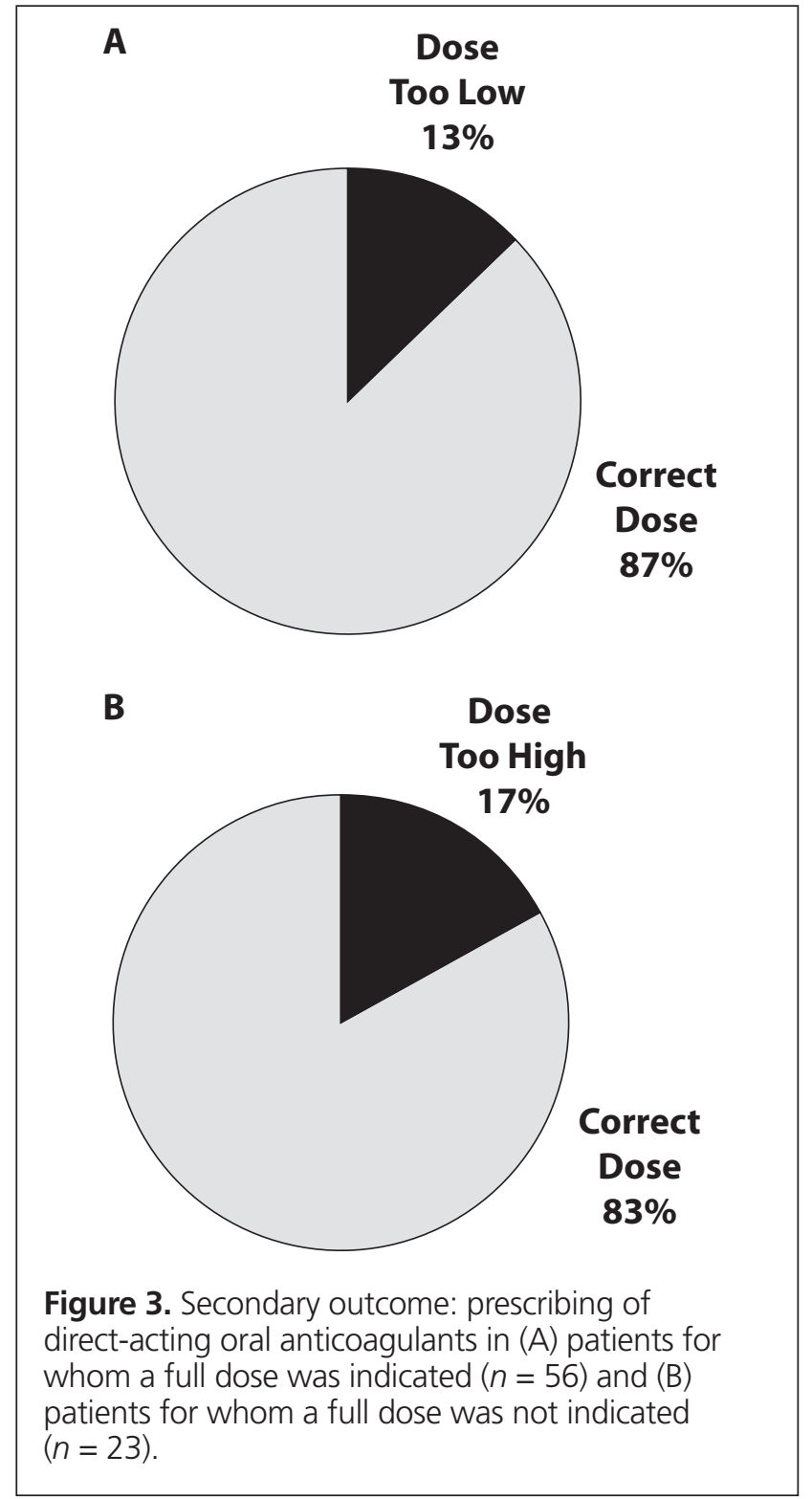

\section{CONCLUSION}

At the ARH, more than two-thirds of patients with NVAF and a CHADS-65 score of 1 or higher had a prescription for a DOAC at discharge, which aligns with the current CCS atrial fibrillation guideline recommendations. Patient characteristics were similar between those receiving warfarin and those receiving a DOAC, although this study was likely underpowered to observe any differences in these characteristics. For most of the patients with a discharge prescription for a DOAC, the drug was correctly prescribed, although $14 \%$ of the patients received a dose that was either too high or too low in relation to the manufacturer's recommendations. Prescribing of oral anticoagulants could likely be further improved by education of prescribers and involvement of hospital pharmacists. 
This single copy is for your personal, non-commercial use only.

For permission to reprint multiple copies or to order presentation-ready copies for distribution, contact CJHP at publications@cshp.pharmacy

References

1. Atrial fibrillation. Ottawa (ON): Heart and Stroke Foundation of Canada; 2018 [cited 2019 Nov 12]. Available from: https://www.heartandstroke.ca/ heart/conditions/atrial-fibrillation

2. Kim YH, Roh SY. The mechanism of and preventive therapy for stroke in patients with atrial fibrillation. J Stroke. 2016;18(2):129-37.

3. Hart R, Pearce L, Aguilar M. Meta-analysis: antithrombotic therapy to prevent stroke in patients who have nonvalvular atrial fibrillation. Ann Intern Med. 2007;146(12):857-67.

4. Connolly SJ, Pogue J, Hart R, Pfeffer M, Hohnloser S, Chrolavicius S, et al. Clopidogrel plus aspirin versus oral anticoagulation for atrial fibrillation in the Atrial fibrillation Clopidogrel Trial with Irbesartan for prevention of Vascular Events (ACTIVE W): a randomised controlled trial. Lancet. 2006;367(9526):1903-12.

5. January C, Wann L, Alpert J, Calkins H, Cigarroa J, Cleveland J, et al. 2014 AHA/ACC/HRS guideline for the management of patients with atrial fibrillation. J Am Coll Cardiol. 2014;64(21):e1-e76.

6. Macle L, Cairns J, Leblanc K, Tsang T, Skanes A, Cox JL, et al. 2016 focused update of the Canadian Cardiovascular Society guidelines for the management of atrial fibrillation. Can J Cardiol. 2016;32(10):1170-85.

7. Kirchhof P, Benussi S, Kotecha D, Ahlsson A, Atar D, Casadei B, et al. 2016 ESC guidelines for the management of atrial fibrillation developed in collaboration with EACTS. Eur Heart J. 2016;37(38):2893-962.

8. Connolly SJ, Ezekowitz MD, Yusuf S, Eikelboom J, Oldgren J, Parekh A, et al. Dabigatran versus warfarin in patients with atrial fibrillation. $N$ Engl J Med. 2009;361(12):1139-51.

9. Patel MR, Mahaffey KW, Garg J, Pan G, Singer DE, Hacke W, et al. Rivaroxaban versus warfarin in nonvalvular atrial fibrillation. $N$ Engl J Med. 2011;365(10):883-91.

10. Granger CB, Alexander JH, McMurray JV, Lopes RD, Hylek E, Hanna M, et al. Apixaban versus warfarin in patients with atrial fibrillation. $N$ Engl J Med. 2011;365(11):981-92.

11. Giugliano RP, Ruff CT, Braunwald E, Murphy SA, Wiviott SD, Halperin $\mathrm{JL}$, et al. Edoxaban versus warfarin in patients with atrial fibrillation. NEngl JMed. 2013;369(22):2093-104.

12. Lee LH. DOACs - advances and limitations in real world. Thromb J. 2016;14(Suppl 1):17.

13. Xu Y, Holbrook AM, Simpson CS, Dowlatshahi D, Johnson AP. Prescribing patterns of novel oral anticoagulants following regulatory approval for atrial fibrillation in Ontario, Canada: a population-based descriptive analysis. CMAJ Open. 2013;1(3):E115-9.

14. Lip GY, Laroche C, Dan GA, Santini M, Kalarus Z, Rasmussen LH, et al. A prospective survey in European Society of Cardiology member countries of atrial fibrillation management: baseline results of EURObservational Research Programme Atrial Fibrillation (EORP-AF) Pilot General Registry. Europace. 2014;16(3):308-19.

15. Steinberg BA, Holmes DN, Piccini JP, Ansell J, Chang P, Fonarow GC, et al. Early adoption of dabigatran and its dosing in US patients with atrial fibrillation: results from the outcomes registry for better informed treatment of atrial fibrillation. J Am Heart Assoc. 2013;2(6):e000535.

16. Yao X, Shah ND, Sangaralingham LR, Gersh BJ, Noseworthy PA. Nonvitamin $\mathrm{K}$ antagonist oral anticoagulant dosing in patients with atrial fibrillation and renal dysfunction. J Am Coll Cardiol. 2017;69(23):2779-90.

17. Pisters R, Lane DA, Nieuwlaat R, de Vos CB, Crijns HJ, Lip GY. A novel user-friendly score (HAS-BLED) to assess 1-year risk of major bleeding in patients with atrial fibrillation: the Euro Heart Survey. Chest. 2010; 138(5):1093-100.

18. Heidbuchel H, Verhamme P, Alings M, Antz M, Diener H, Hacke W, et al.; ESC Scientific Document Group. Updated European Heart Rhythm Association practical guide on the use of non-vitamin-K antagonist anticoagulants in patients with non-valvular atrial fibrillation: executive summary. Eur Heart J. 2017;38(27):2137-49.
19. Man-Son-Hing M, Nichol G, Lau A, Laupacis A. Choosing antithrombotic therapy for elderly patients with atrial fibrillation who are at risk for falls. Arch Intern Med. 1999;159(7):677-85.

20. AbuDagga A, Stephenson JJ, Fu AC, Kwong WJ, Tan H, Weintraub WS Characteristics affecting oral anticoagulant therapy choice among patients with non-valvular atrial fibrillation: a retrospective claims analysis. $B M C$ Health Serv Res. 2014;14:310.

21. Desai NR, Krumme AA, Schneeweiss S, Shrank WH, Brill G, Pezalla EJ, et al. Patterns of initiation of oral anticoagulants in patients with atrial fibrillation - quality and cost implications. Am J Med. 2014;127(11):1075-82.

22. Tagaya M, Yoshikawa D, Sugishita Y, Yamauchi F, Ito T, Kamada T, et al. Prescription patterns of oral anticoagulants for patients with non-valvular atrial fibrillation: experience at a Japanese single institution. Heart Vessels. 2016;31(6):957-62.

23. Brais C, Larochelle J, Turgeon M, Tousignant A, Blais L, Perreault S, et al. Patterns of oral anticoagulants use in atrial fibrillation. J Popul Ther Clin Pharmacol. 2015;22(1):e90-5.

24. Alamneh EA, Chalmers L, Bereznicki LR. Suboptimal use of oral anticoagulants in atrial fibrillation: has the introduction of direct oral anticoagulants improved prescribing practices? Am J Cardiovasc Drugs. 2016;16(3) 183-200.

25. Special authority request-apixaban/dabigatran/rivaroxaban for atrial fibrillation. Victoria (BC): Ministry of Health; 2019 [cited 2019 Nov 12]. Available from: https://www2.gov.bc.ca/assets/gov/health/forms/5391fil.pdf

Priscilla Shum, BSc(Pharm), ACPR, is with the Peace Arch Hospital, Fraser Health Authority, White Rock, British Columbia.

Gordon Klammer, BSC(Pharm), ACPR, BCPS, is with Lower Mainland Pharmacy Services, Abbotsford, British Columbia.

Dale Toews, BSc(Pharm), ACPR, is with Lower Mainland Pharmacy Services, Abbotsford, British Columbia.

Arden Barry, BSC, BSC(Pharm), ACPR, PharmD, is with Lower Mainland Pharmacy Services, Abbotsford, British Columbia, and The University of British Columbia, Vancouver, British Columbia.

Competing interests: None declared.

\section{Address correspondence to:}

Priscilla Shum

Pharmacy

Peace Arch Hospital

15521 Russell Avenue

White Rock BC V4B 5M2

e-mail: priscilla.shum@fraserhealth.ca

Funding: None received.

Acknowledgement: The authors thank Alana Winters for her assistance with data acquisition. 